\title{
Digital learning at the University of Architecture and Civil Engineering: psychological risks and effects
}

\author{
Lyaylya Yarullina*1[0000-0001-5675-2795] \\ ${ }^{1}$ Kazan State University of Architecture and Engineering, 420043 Kazan, Russia
}

\begin{abstract}
The article examines the problem of digital education in high school in terms of its psychological risks and effects. The aim of the work is to identify the psychological effects of the transformation of higher education in the digital age and to determine the priority trends of psychological support in the digital educational process. In the theoretical aspect of this study the analysis of the problem of psychological risks and challenges of digital education in high school is presented on the basis of domestic and foreign experience of transition to a remote format of education. Methods of theoretical analysis of modern sources on this problem were applied, in particular, cognitive and personal-developing approach to professional and professional-pedagogical education. The author refers to the separate articles on digital education in high school. The work analyzes the sociopsychological aspects of digital education reflecting the person-oriented system risks, communicative competence risks, individual psychological security risks and a new type of students in the digital age. The article reveals only some of the psychological effects of digitalization discussed in studies on this issue. As a result, the priority trends of digital education psychological effects in high school were identified.
\end{abstract}

Keywords. Digitalization, digital education, higher education, psychological risks, psychological effects, distance learning, digital technology, transformation of higher education.

\section{Introduction}

Nowadays, the problem of introducing the electronic information innovations and digital technologies into the educational process in high school is seriously debated in scientific and educational communities. In recent years, this topic has been the subject of many scientific forums, scientific and practical conferences on digital learning in higher education. However, the acuteness of the problem has become particularly pronounced in the wake of the COVID19 coronovirus pandemic that has spread throughout the world.

All levels of the educational system, including high school, are moving to a remote format using remote information technologies.

Today's reality is, as Borisova N.B. notes the following «social and political transformations with the key word «digital» (revolution, epoch, economy, personality, education) create new reality, new ethics and a new view on a human being» [1]. In the context of the information

*Corresponding author: lala0609@mail.ru 
boom that has changed the structure of the economies of many countries, society, models of relationships between people, the consciousness of the person living in a new post-industrial environment [2], where digital technologies are coming forward [3].

Online learning has been gaining speed in many Western countries having sufficient experience in such a kind of education [4-6]. Before the crisis, this practice was highly approved by both students and faculty, for example, American universities $[1,7,8]$. Online courses have been actively implemented in the curriculum, providing a large portfolio of remote services $[9,10]$. Many European and Western universities are actively looking for the optimal ratio of remote and traditional education [11].

There is some experience of distance learning in Russian education. Electronic educational resources were introduced into the curriculum of various fields and levels of higher education, the opportunities to work outside the classroom at any convenient time, study simultaneously in various specialties, test knowledge control, etc.

However, the urgent transfer to a qualitatively new, unusual training regime, in particular, in Russian universities became an unexpected challenge for the education system and identified all the weak points and possible risks in both pedagogical and socio-psychological contexts.

This was noticed by the Minister of Science and Higher Education of the Russian Federation, Falkov V.N., who in his interview with the RBC News agency on April 9, 2020 emphasized that the most difficult thing for teachers in using a remote format is to «organize collective work, to keep the students attention and interest, to make the studying process interesting though, in fact, we have emotional and intellectual moments go asynchronously» [12].

Hence, the study of the psychological risks and challenges of digital education in high school based on the analysis of domestic and foreign experience of transition to a remote format of education is relevant and practically significant, as it contributes to the search for new measures of introduction of digital technologies into higher education [13].

The aim of the scientific work is to identify the psychological effects of the transformation of higher education in the digital age and to prioritize psychological support in the digital educational process.

\section{Materials and methods}

The study was conducted on the basis of methods of theoretical analysis of modern sources on this problem, using cognitive and personal-developing approaches to professional education (Verbitsky A., Zeer E.F.) [7, 14]. The materials of separate articles on digital education in high school were also used in terms of their pedagogical risks and challenges (Tulchinsky G.A., 2017; Kochergin D.G., Kolesnikova I.A., 2019; Mikhailov O.V.), on issues of improving the quality of education and teaching in digital conditions (Lukin V., Dikarev V.A., 2018; Shayakhmetova V.R., 2019), cognitive didactic concepts (Kamaleeva A.R., 2020); socio-psychological aspects, expressing the risks of the system of person valueand-meaning orientations (Ignatova N. I., 2017; Borisova N.B., 2018, Kolykhmatov, 2018), communicative competences (Verbitsky A., Kirilova G.I., Donskikh O.A., 2020), psychological personal security (Morozov, 2019, Bayeva, 2020).

\section{Results}

Critical analysis of contemporary scientific researches, considering all the possibilities and consequences of the impact of digital technologies on higher education, has revealed a number of risks in this sphere.

The post-industrial revolution dictates its own «rules of the game» in higher education, which cannot be ignored. Thus, Verbitsky V.V. analysing the problem of the implementation 
of digital education states that «there is a necessity to transition to a practice-oriented type of continuous education based on the science fundamental content and on man's inexhaustible capabilities as a subject of general and professional development, including huge opportunities of digital means of learning». However, «there is no pedagogical or psychological-educational theory of digital learning which school teachers, teachers of colleges and universities can rely on» [7].

Noting the advantages of digital learning, Lukin V.V., Dikarev V.A. emphasize the expansion of creativity, development of critical thinking, the transformation of the teacher - student interaction. Shayakhmetova V.R. believes that modern information technologies contribute to improving the quality of training and teaching, transferring them to a new level of requirements, but this requires new competences of teachers that meet the requirements of our time [15].

Zeer E.F. emphasizes that personal-oriented education should create conditions for developing the ability to self-education, self-determination, independence and self-realization.

At the same time, «the bringing up of a new type of a specialist able to plan, design and predict their professional activity and adequately assess its results is possible in new conditions only if the educational programs and implementing them teachers of colleges and universities will be aimed at developing of certain skills of self-education [14].

According to Tulchinsky G.A., digitalization requires new competencies from university graduates, which are sometimes acquired outside the limits of educational institutions. As today's reality shows, digital competence should be ahead of the crisis situations. Teachers with traditional lectures are not competitive and are not claimed» [16].

Kolesnikova I.A. believes that online training requires from the student not only high motivation, but also the ability to self-education. Modern university education should form the readiness of the graduate to any changes, to see the prospects, to make them independent from limited knowledge, to accept new digital technology approaches [17].

The need to transform the modern high school didactics is emphasized by Kamaleyeva A.R., who considers the task of pedagogical process within the framework of cognitive didactics in «creating conditions for the development of effective cognitive organization of a person, supplying them with universal tools for solving educational and life problems». Such tools are designed to prepare university students for life in a digital society and to meet the requirements of the employers in the digital economy [18].

Digital devices and technologies are the result of natural scientific knowledge (mathematics, engineering, technocracy), and at the heart of the process of education in high school is psyco-pedagogical knowledge, including pedagogical psychology, pedagogy and psychology of higher education, psychology of personality, social psychology, psychology of communication, etc. In the process of information transfer, along with important cognitive are the meaning- forming, motivational, regulatory components of communication.

The above discussed aspects of digital education in high school mainly relate to the pedagogical and philosophical aspects of the transformation of higher education, caused by the new realities. Analysis of sources and literature while studying of the psychological context of the problem of digitalization in general, and the digitization of education, in particular, revealed that the problem was not sufficiently examined and there is still a problem field for further research of the scientific community. The analyzed aspects presented in the article show that there are some materials that have determined the psychological effects of digital education in high school, such as problems concerning the communicative competence of the system of value-sense orientations of the person, man's psychological security.

As Donskikh O.A. notes, «the problem of changing the nature of communication is more serious. Thus, the use of video conferencing systems such as Zoom, Skype or TrueConf, etc., which allow you to simulate normal communication, gives the illusion of presence, but it quickly turns out that such communication is much more intensive but less effective. Remote 
communication has a negative impact, for example, on reading and in general on communication processes [5].

Academician Verbitsky A.A. believes that it is important to distinguish between information and knowledge, these are different concepts. If the information is «a carrier of meanings (language signs, texts, speech sounds), then knowledge is a substructure of personality, something subjective, personal meanings, which are often different for different people who perceive the same information». Communication includes communicative, perceptive and interactive components. Social perception allows us to perceive thoughts, emotions, feelings of another person. Reflection and sometimes empathy take place in the process of interaction between a teacher and a student. This can be achieved through communication, including verbal and non-verbal means (kinesthetic, extra-paralinguistic and other means). Digital means are not able to comprehend this, we need «real communication», «live emotions». It is important to understand, as Verbitsky A.A. notes, «there is a real risk of speech degradation, as well as of thinking, because it has its place in speech, which in digital learning is reduced to the user's clicking on the letters on the computer keyboard» [7].

According to Mikhailov O.V. distance education can become prevalent only in completely unique situations, in which «live» communication between people in general, between teachers and students, in particular, for some reasons should be minimized or even excluded [19].

Studies show that as a result of the introduction of digital and informational technologies in training significantly accelerated the transmission of information, facilitated its search on the Internet, but there appeared also negative indicators: there are some changes in people's mentality, in the development of their mental abilities. Some cognitive skills are developed at the expense of others and as a result the so-called «clip thinking» is formed. Speech becomes uncoordinated, poor and «clipped» (Kalkeeva, Kalimzhanova, 2018).

Search for quick answers in network leads to «mental poverty», unwillingness to think. As the famous thinker Rene Descartes said, «thinking means that I exist». Cognitive abilities are being lost; speech is becoming degraded.

The risks of digitalization also affected one of the basic human needs - security. According to Krasnyanskaya T.M., the certain threats for human security as a user of digital innovation can manifest themselves at different levels. Thus, we can distinguish the following levels of security: «the individual is informational and psychological security, the subject is subjective security, the person is the socio-psychological security, the individuality is the psychological security of the person» [16].

All these levels of security are evident in students in the process of their studies. The educational process is carried out in the human-person system, where each participant is the subject of social interaction.

Digital learning includes information tools into the interaction process that disrupt the perceptive contact between the subjects and rebuild their communication space. The meaning of the communication is not true, as the information media do not have the interpersonal perception and communication capabilities that the subject of interaction possesses. Hence, the knowledge gained by means of digitalization is not real knowledge [1].

Bayeva I.A. and Burmistrova E.V., note that the educational process can be considered effective only if each of the participants of the «subject-subject» interaction maintains the informational and psychological security of the person. A mechanism of protection against informational influences aimed at changing the psycho-emotional state of the person and their behavior should be provided.

Thus, the results of Kazan State University of Architecture and Engineering students' survey on distance learning in the context of the COVID-19 coronavirus pandemic made it possible to draw some conclusions. In determining the emotional condition, it was revealed that more than $63 \%$ of students experience discomfort in the new format of training, as the 
reasons are indicated changes in the usual schedule, lack of live communication. The psychological state of the students is determined as stressful [3].

At the same time, the change in the roles of the subjects of the educational process is clearly defined. As Kramarenko N.S. notes, the teacher becomes rather a «carrier, a translator of knowledge, becoming rather a guide in the information space». Their role becomes mediated by informational resources. The teacher looks like a commentator whose role is to help «learners navigate the information flow and organize the information they have already found» [19].

Among the psychological effects of digital learning at the personal level is the change of outlook of value system and social settings of educational process (Morozov, 2019). According to Kolykhmatov V.I. «changes in personal aspirations, attitude to violence, emotional maturity, formation of the value system, self-esteem, the presence of authority» [15] can be attributed to individual risks of digitalization.

Values orientations change their perspective and create a new type of a student and a teacher in the higher education system, where values and social settings are becoming the primary, caused by the orientations of the digital epoch. Generation Z (digital native) individualists focused on short-term goals, fragmently and superficially thinking, but capable for self-education, for obtaining information themselves, easily orienting in social networks, on the Internet $[20,21]$. This new type of people already lives in the phygital-world and is best prepared for its innovative trends, sees no difference between virtuality and reality. As noted by Mamin R.I. and Tolstikova I.I., the accents of the new generation are directed at individual values, publicity and personalization are cultivated [22].

In today's world, there are new values of digital civilization at all levels of interaction. Thus, we can conclude that digitalization changes the axioms of education, changes the space (topos) and the time of the human life (temporability) [23].

The article reveals only some of the psychological effects of digitalization discussed in studies on this issue. It is obvious that there is a need for new researches of psychological challenges and risks of digital learning in high school, methodological vectors that guide and organize scientific research in this sphere.

\section{Discussion}

One of the priorities of higher education is the development of the personality of the student [24], the preservation of psychological comfort to ensure their self-fulfillment in a dynamic environment in the digital age.

Theoretical analysis of existing studies related to the risks of digital education in high school in terms of their psychological effects has led to the following conclusions:

1. There is no psychological and pedagogical theory of digital learning that would form the basis for teaching in high school and provide the optimal combination of traditional and virtual learning; determine the role of participants in the educational process.

2. There is a transformation of the didactic higher education, new requirements for the quality of education. A new model of education requires new competencies from the teacher, supporting their competitiveness at the market of educational service. There are new guidelines of digital education, requiring special psychological training of teachers who are ready to work ahead in any crisis situations, and students who meet the requirements of the employer in the digital economy [25].

3. It was estimated that most of the psychological risks are related to the restructuring of interpersonal communications of subjects of the educational process. Digital communication lacks a perceptual component. Information resources are not sufficiently able to carry out reflection, empathy between the teacher and the students, there is no perceptual exchange between students. Information does not give full knowledge. Speech degrades. 
4. There is a threat to violation of the information and psychological security of the person, which provides psychological comfort to the personality of the student and the teacher, positive development and mental health in the process of pedagogical interaction. Information innovation should not have a negative impact on the emotional and psychological state of the personality of the subjects of educational interaction.

5. There is a change in the roles of the subjects of the educational process. «Subjectsubject» interaction changes its field, it is mediated by digital means.

6. A new type of a student is being formed to change the perspective of values, social settings, worldviews, type of thinking, which are more aimed at meeting the demands of the digital age.

The obtained results demonstrate the importance of taking into account the risks of digital education in high school, in particular its psychological effects, as well as prioritizing areas of psychological support and improvement in the digital environment of interpersonal interaction of subjects of the educational process.

\section{References}

1. L. Yarullina, D. Shigapova, L. Abdrahmanova, T. Suchkova, A. Barieva, E. Nikonova, IOP Conf. Ser. Mater. Sci. Eng. Institute of Physics Publishing, (2020). DOI: 10.1088/1757-899X/890/1/012171.

2. A. Kukulska-Hulme, IITE Policy Br. 3, 1 (2010).

3. L.R. Yarullina, World Sci. Pedagog. Psychol. 6, 2PSMN620 (2020).

4. Y.L., P.S., In-Depth 33 (2), 1 (2013).

5. O. Donskikh, High. Educ. Russ. 29 (10), 56 (2020). DOI: https://doi.org/10.31992/08693617-2020-29-10-56-64.

6. I. Menter, R. Valeeva, A. Kalimullin, Eur. J. Teach. Educ. 40 (5), 616 (2017). DOI: 10.1080/02619 768.2017.1385060.

7. A. Verbitsky, Homo Cyberus 1, 6 (2019).

8. D. Kochergin, E. Gernov, Vocat. Educ. Russ. Abroad 2 (34), 12 (2019).

9. J. Traxler, Int. J. Mob. Blended Learn. 1, 1 (2009). DOI: 10.4018/jmbl.2009010101.

10. P. Driver, Int. J. Comput. Assist. Lang. Learn. Teach. 2 (4), 23 (2012). DOI: 10.4018/ijcallt.2012100104.

11. I. Gafurov, R. Valeeva, A. Kalimullin, Educ. Self Dev. 14 (3), 6 (2019). DOI: 10.26907/ esd14.3.01.

12. I. Gafurov, G. Ibragimov, A. Kalimullin, T. Alishev, High. Educ. Russ. 29 (10), 101 (2020). DOI: 10.31992/0869-3617-2020-29-10-101-112.

13. R.A., L. Yarullina, R. Safin, I. Vildanov, Izv. KGASU 3 (17), 277 (2011).

14. E. Seeer, V. Tretyakova, V. Miroshnichenko, Educ. Sci. 21, 93 (2019). DOI: 10.17853/1994-5639-2019-6-93-121.

15. T. Krasnyanskaya, V. Tylets, Knowledge. Understanding. Ski. 2, 152 (2020). DOI: 10.17805/sp.2020.2.14

16. G. Tulchinsky, Philos. Sci. 6, 121 (2017).

17. I. Kolesnikova, High. Educ. Russ. 28 (9), 67 (2019). DOI: 10.31992/0869-3617-2019-28-8-9-67-82.

18. A. Kamaleeva, Kazan Teach. J. 4 (141), 31 (2020).

19. N. Kramarenko, A. Kvashnin, J. MRSU 4, 1 (2017).

20. N. Ignatova, Open Distance Educ. 1 (65), 58 (2017). DOI: 10.17223/16095944/65/8.

21. O. Mikhailov, J. Denisova, High. Educ. Russ. 29 (10), 65 (2020). DOI: 10.31992/08693617-2020-29-10-65-76.

22. R. Mamina, I. Tolstikova, Discurs 5, 29 (2019). DOI: 10.32603/2412-8562-2019-5-6-29-41.

23. M. Janitzky, Vocat. Educ. Russ. Abroad 12 (34), 38 (2019).

24. M. M.S., M. N.A., Gumanit. Nauk. v XXI Veke 8, 47 (2017).

25. B. E.V., Balt. Humanit. J. 1 (34), 43 (2021). DOI: 10.26140/bgz3-2021-1001-0009. 